\title{
PIROXÊNIOS E O CAMINHAMENTO P-T NA FÁCIES GRANULITO DO SW DE MINAS GERAIS, BRASIL
}

\author{
A.Choudhuri ${ }^{1}$, S.S.Iyer ${ }^{2}$
}

Rochas de fácies granulito freqüentemente contêm piroxênios com exsolução característica devido ao resfriamento subseqüente às temperaturas de pico metamórfico. Análises totais integradas desses piroxênios têm fornecido composições relacionadas à sua história ígnea pré-metamórfica ou ao próprio evento granulítico de alta temperatura (Bohlen \& Essene, 1978; Sandiford \& Powell, 1986). No último caso, as temperaturas devem ser próximas dos valores máximos anteriores ao resfriamento e exsolução, além de revelar aspectos relacionados à natureza das transformações cristalográficas dos piroxênios. Em vista da importância dos piroxênios na fácies granulito, a petrografia de ortopiroxênio e piroxênio cálcico coexistentes do SW de Minas Gerais são reportados aqui, e a sua temperatura de equilibrio é estimada com base no método de Wood \& Bannos (1973).

Os piroxênios aqui estudados pertencem ao terreno de alto grau Guaxupé (Maciço Guaxupé ou nappe Guaxupé). As rochas hospedeiras podem ser classificadas na suite charnoquítica, com composições variando de charnoquito até mangerito, e contento mesopertita, quartzo, plagioclásio, orto e clinopiroxênios, raro anfibólio verde-escuro - provavelmente hornblenda-, e biotita; minerais acessórios são zircão, em cristais bem formados, apatita, em um caso granada, e opacos ainda não identificados. Feições de campo e texturais dessas rochas sugerem sua colocação sin-tectônica na fácies granulito sob condições de deficiência em água e na presença de fluidos de alto $\mathrm{CO}_{2}$ (Choudhuri et al., 1995). Duas hospedeiras dos piroxênios analisados são, contudo, um enderbito máfico e um granulito máfico, respectivamente.

Tanto o orto- como o clinopiroxênio são muito fortemente coloridos, o primeiro pleocróico de esverdeado a buff, e o último verde intenso e não pleocróico. Os piroxênios têm formas irregulares e ocorrem como trilhas paralelas à foliação gnáissica das rochas. Os ortopiroxênios contêm exsoluções muito finas de lamelas de clinopiroxênio segundo (100), e hospedeira e lamelas podem ser facilmente distinguidas por suas cores de interferência e extinção. Muitos clinopiroxênios têm lamelas de exsolução paralelas a (001), mas alguns deles mostram um conjunto de exsoluções complexas. Nestes, as lamelas de exsolução (001) são mais proeminentes, com muitas lamelas mais finas (100) entre elas e, por vezes, um segundo conjunto de lamelas muito finas (001) (Fig. 1). As lamelas (001) principais têm largura de apenas $5 \mu \mathrm{m}$ ou menos, enquanto as lamelas (100) e o segundo conjunto (001) são da ordem de $1 \mu \mathrm{m}$. Tal feição contrasta com as exsoluções largas encontradas em rochas ígneas. Curiosamente, algumas amostras contêm clinopiroxênio cálcico no qual tanto a hospedeira como as lamelas de exsolução mostram extinção inclinada, e essas lamelas podem ser de pigeonita não-invertida. As orientações aproximadas da hospedeira e lamelas são mostradas na Figura 1. A partir dos exemplos dados por Ollila et al. (1988), pode-se conjecturar que no caso do clinopiroxênio cálcico com lamelas

\footnotetext{
${ }^{1}$ Instituto de Geociências, Universidade Estadual de Campinas.

${ }^{2}$ Dept. of Physics and Astronomy, Fac. Science, University of Calcary, Alberta, Canada.
} 
complexas, lamelas de pigeonita exsolveram ao longo de (001) e então inverteram para ortopiroxênio, após o que a hospedeira exsolveu mais ortopiroxênio ao longo de (100) e (001). Todas essas lamelas são finas demais para análise, e em conseqüência as estimativas de temperatura são baseadas em análises integradas.

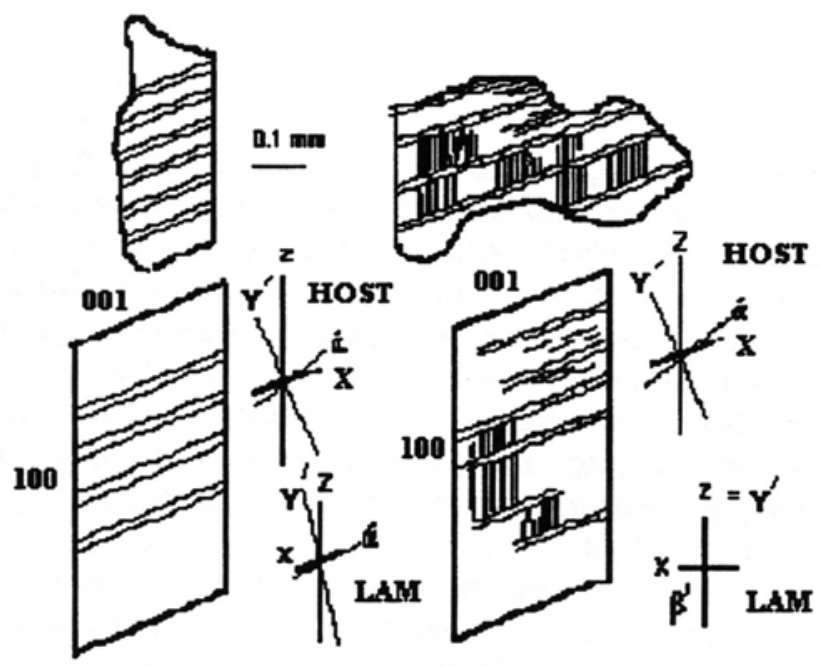

Figura 1 - Exsolução em clinopiroxênios cálcicos vista em secções próximas a (010) com orientação aproximada para hospedeira e lamelas (LAM); no segundo clinopiroxênio, há três exsoluções - ver texto.

Como se esperaria de suas cores fortes, os piroxênios são usualmente ricos em ferro. $\mathrm{O}$ conteúdo de $\mathrm{FeO}$ dos ortopiroxênios varia de 42 a $48 \%$, e o do clinopiroxênio cálcico de 25 a $28 \%$; suas razões $\mathrm{Mg} / \mathrm{Mg}+\mathrm{Fe}$ situam-se no intervalo 0,21 a 0,06 . Neste sentido, eles são muito semelhantes aos piroxênios da suite mangerito-charnoquítica de Lofoten, Noruega (Ormaasen, 1977). Estes últimos, contudo, se formaram por reações envolvendo faialita, para as quais não há indicações nas rochas aqui estudadas.

$\mathrm{Na}$ área de São José do Rio Pardo, ao sul de Guaxupé, Oliveira \& Hypólito (1978) correlacionaram as composições dos piroxênios com as das rochas totais, e a composição rica em ferro das rochas hospedeiras é possivelmente uma das razões para os piroxênios serem também ricos em ferro. No diagrama de $\mathrm{K}_{\mathrm{D}}$ usual os piroxênios se distribuem ao longo de uma curva suave com um valor médio de 0,65 , próximo ao valor reportado pelos autores acima. Este valor está próximo do limite para piroxênios metamórficos (ver por exemplo Kretz, 1961; Sen \& Manna, 1976), e atesta seu equilibrio sob condições de fácies granulito (Fig. 2).

Estimativas de temperatura baseadas no método de Wood \& Bannos (1973) fornecem um intervalo de $786^{\circ}$ a $833^{\circ} \mathrm{C}$, com uma média em torno de $809^{\circ} \mathrm{C}$. Este valor é comparável com os valores $840 \pm 40^{\circ} \mathrm{C}$ e $780 \pm 60^{\circ} \mathrm{C}$ obtidos por Oliveira \& Hypólito (1978) e por Santos (1988), respectivamente. Resfriamento a partir dessas temperaturas levou à exsolução tanto no ortopiroxênio como no clinopiroxênio cálcico, e nós sugerimos que isto ocorreu ao longo do caminho de descompressão estabelecido para os granulitos do Guaxupé (Iyer et al., 1966; Choudhuri et al., 1995). Isto quer dizer que os piroxênios também devem ter seguido o caminho $\mathrm{P}-\mathrm{T}$ de $8,5 \mathrm{~kb}-850^{\circ} \mathrm{C}$ até $6,0 \mathrm{~kb}-650^{\circ} \mathrm{C}$, já que sua temperatura de equilíbrio está próxima da temperatura de pico metamórfico, e sua exsolução é uma evidência de resfriamento. A 
temperatura mais baixa final é contudo duvidosa devido à escala muito fina da exsolução que impede a análise no momento. Nós nos baseamos portanto nos dados P-T obtidos para especular que os piroxênios seguiram esse caminhamento.

\section{KD opx-Ca-cpx}

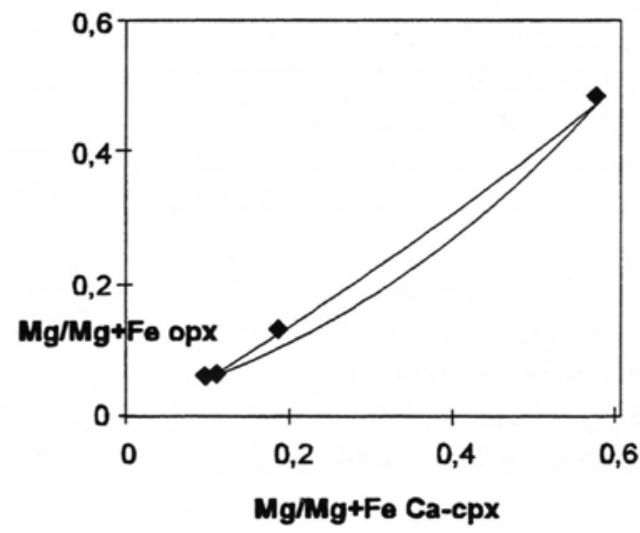

Figura 2 - Distribuição de Mg e Fe para clinopiroxênio cálcico e ortopiroxênio coexistentes - $K_{D}$ $=0,65$. A segunda curva, sem pontos, representa piroxênios de Sen \& Manna (1976), para os quais $\mathrm{K}_{\mathrm{D}}=0,55$.

\section{Agradecimentos}

Dedicamos esta breve comunicação à memória de Mario Figueiredo, cujo dinamismo e natureza amistosa freqüentemente trouxeram idéias novas para os que trabalham em áreas de alto grau. Agradecemos ao Prof. Dr. J. Touret pelas análises de piroxênios; A.C. é grato ao CNPq pelo apoio financeiro.

\section{Referências Bibliográficas}

BOHLEN, S.R.; ESSENE, E.J. (1978) Igneous pyroxenes from metamorphosed anorthosite massifs. Contributions to Mineralogy and Petrology, v.65, p.433-422.

CHOUDHURI, A.; SILVA, D.; NOGUEIRA, J.R.; SZABÓ, G. (1995) Granulite facies rocks from Guaxupé, MG: gneiss-fluid sequences and P-T conditions. Geonomos, v.3, n.2, p.4349.

IYER, S.S.; CHOUDHURI, A.; PATTISON, D.R.M.; DE PAOLI, G.R. (1966) Petrology and geochemistry of the Neoproterozoic Guaxupé granulite facies terrain, southeastern Brazil. Precambrian Research, v.77, p.23-40.

KRETZ, R. (1961) Some applications of thermodynamics to coexisting minerals of variable compositions. Examples: orthopyroxene-clinopyroxene and orthopyroxene-garnet. Journal of Geology, v.69, p.361-387. 
OLIVEIRA, M.A.F.; HYPÓLITO, R. (1978) Ortopiroxênios e clinopiroxênios coexistentes nos granulitos de São José do Rio Pardo, SP. Revista Brasileira de Geociências, v.8, p.249-261.

OLLILA, P.W.; JAFFE, H.W.; JAFFE, E. (1988) Pyroxene exsolution: An indicator of highpressure igneous crystallization of pyroxene-bearing quartz syenites from the High Peaks region of the Adirondack Mountains. American Mineralogist, v.73, p.261-273.

ORMAASEN, D.E. (1977) Petrology of the Hopen mangerite-charnockite intrusion, Lofoten, north Norway. Lithos, v.10, p.291-310.

SANDIFORD, M.; POWELL, R. (1986) Pyroxene exsolution in granulites from Fyfe Hills, Enderby Land, Antarctica: evidence for $1000^{\circ} \mathrm{C}$ metamorphic temperatures in Archean continental crust. American Mineralogist, v.71, p.946-954.

SANTOS, A.M. (1988) Caracterização petrológica dos granulitos básicos da folha de Guaranésia (MG). São Paulo, 160p. (Dissertação - Mestrado) - Instituto de Geociências, Universidade de São Paulo.

SEN, S.K.; MANNA, S.S. (1976) Patterns of cation fractionation among pyroxenes, hornblende and garnet in the basic granulites of Saltora, West Bengal, Indian. Indian Journal of Earth Science, v.3, p.117-128.

WOOD, B.J.; BANNO, S. (1973) Garnet-orthopyroxene and orthopyroxene-clinopyroxene relationships in simple and comples systems. Contributions to Mineralogy and Petrology, v.42, p.109-124. 